\title{
The Goggles Project: Using Street Theatre to Engage University Stakeholders in Discussions about Sustainability
}

\author{
Tarah Wright $^{1^{*}}$, Gary Markle ${ }^{2}$, Peter Wuench ${ }^{3}$ \\ ${ }^{1}$ Environmental Science, Faculty of Science, Dalhousie University, Halifax, Canada \\ ${ }^{2}$ Nova Scotia College of Art and Design, Halifax, Canada \\ ${ }^{3}$ Breakhouse Inc., Halifax, Canada \\ Email: "Tarah.Wright@dal.ca
}

Received May $15^{\text {th }}, 2013$; revised June $15^{\text {th }}$, 2013; accepted June $22^{\text {nd }}, 2013$

Copyright (c) 2013 Tarah Wright et al. This is an open access article distributed under the Creative Commons Attribution License, which permits unrestricted use, distribution, and reproduction in any medium, provided the original work is properly cited.

Sustainable development has become a global priority. While a sustainable future cannot be achieved through changes and actions in one sector alone, education is a key component in working toward this goal. Universities in particular have a moral task as leaders in the ESD movement, and are important catalysts for moving towards a sustainable future. However, research shows that there is a general lack of engagement in, and knowledge of sustainability within the university community at large. This manuscript describes the Goggles Project which used street theatre as a creative way to engage the whole university community in discussions regarding sustainability and the role universities can and/or should play in achieving a sustainable future.

Keywords: Sustainability in Higher Education; Sustainable Development; Street Theatre; Education for Sustainable Development

\section{Background-Sustainability in Higher Education}

Over the past few decades, humanity has become more aware of the growing number of environmental problems that threaten human and ecosystem health. The ramifications of environmental degradation have led many governments and international agencies to highlight the need for human development to be based on principles of sustainable development (SD). The World Commission on Environment and Development (WCED) defines SD as "meeting the needs of the present without compromising the ability of future generations to meet their own needs" (WCED, 1987: p. 43). The main tenets of sustainable development are focuses on integrating ecological, economic and social considerations into decision making; inter-generational equity; increasing equity within nations and amongst developed and developing countries (intra-generational equity); reducing population growth; and, conserving and enhancing the resource base.

While a sustainable future cannot be achieved through changes and actions in one sector alone, education is a key component in working toward this goal ((Bachiorri \& Puglisi, 2007; Cortese, 2003; Orr, 1992; UNESCO, 2005). The concept of education for sustainable development (ESD) asserts a vision of education that empowers people to assume responsibility for creating sustainable societies. ESD has become so important to the global sustainability movement that the United Nations declared 2005-2014 the United Nations Decade of Education for Sustainable Development (United Nations, 2002).

\footnotetext{
*Corresponding author
}

Universities in particular have a moral task as leaders in the ESD movement, and are important catalysts for moving towards a sustainable future (Orr, 1992; UNESCO-UNEP, 1978). Clugston (1999) explains that universities are vested by society with the task of discerning truth, imparting values, and socializing students to contribute to social progress and the advancement of knowledge. Higher education has a responsibility to impart the moral vision and technical knowledge needed to ensure a high quality of life for future generations. According to the United Nations Educational, Scientific and Cultural Organization, "the goal of (higher) education is to make people wiser, more knowledgeable, better informed, ethical, responsible, critical and capable of continuing to learn. Education, in short, is humanity's best hope and most effective means in the quest to achieve sustainable development” (UNESCO, 1997).

The desire to consider sustainability within the university has been translated into a number of initiatives. Several emerging themes demonstrate how universities frame the central task of becoming leaders in sustainable development, and include: engagement in environmental literacy initiatives; curriculum development; research related to sustainability; partnerships with government, non-governmental organizations and industry in developing sustainability initiatives; and, "greening” physical operations (Wright, 2004).

Although several advances have been made in SHE research, major university stakeholders have remained largely absent in discussions regarding the role universities can play in creating sustainable societies (Wright, 2010). This is a major issue, as research shows that all university stakeholders (administrators, students, staff, and faculty) must be engaged in discussions in 
order to ensure the long-term success of sustainability initiatives (Filho, 2005; Newman \& Abrams, 2005).

Scholarly research shows that outreach can be a major vector in creating change (Filho, 2000; Oepen, 2000) and an often neglected factor in social learning and change processes (Ornetzeder \& Rohracher, 2005). Much of the literature contends that engaging with key stakeholder groups in developing a vision for change is paramount to ensuring that change efforts within the institution bear fruit (de la Harpe \& Thomas, 2009; Kezar \& Eckle, 2002; Kezar, 2009; Wals \& Jickling, 2002). McMillin \& Dyball (2009) posit that all university stakeholders must be engaged in discussions of sustainability for it to be realized at an institution. Filho (2005) states that to be successful, the sustainability in higher education movement must engage in stakeholder discussions and the integration of the whole university community into decision-making and communication (Filho, 2005). Finally, Wright (2010) argues that there is a general lack of engagement in, and knowledge of sustainability within the university community at large - which in turn can hinder progress to developing sustainability initiatives on campus.

But how can we best engage university stakeholders in dialogue about sustainability in higher education? How can we reach those who are not already involved with sustainability initiatives on campus (i.e. reach beyond "the choir")? The Goggles Project that we describe below was designed to engage the whole university community in discussions regarding the role universities can and/or should play in achieving a sustainable future in a creative way.

\section{The Genesis of the Goggles Project}

The story of the Goggles Project begins at a party, where a couple of friends from different academic backgrounds and employment experiences (i.e. science, architecture, and fashion design), but with a shared vision for a sustainable future, were discussing how to provoke sustainability discussions and engage the entire university community in thinking about the role that higher education could play in the sustainability movement. Many ideas were thrown around, including holding focus groups on campuses and sustainability lecture tours, but none felt like they could reach out far enough amongst the various stakeholders within the institution. It was further determined that these ideas were relatively boring, and would not serve to inspire any excitement amongst stakeholders who are not currently involved in sustainability on campus.

Sustainability problems are complex, and while traditional delivery methods (lectures, public talks, etc.) serve to inform individuals, they have been criticized in the past for failing to promote a full understanding or appreciation of sustainability issues as a whole:

No amount of preaching to the citizenry about the perils of a polluted environment, the dangers of irresponsible disposal of wastes or deforestation and the benefit to mankind [sic] of greening the environment will make people act to seek to forestall environmental degradation unless they are imbued with a deep concern for the common good, a sense of responsibility for maintaining a balanced and healthy ecosystem and a strong drive to achieve harmony with nature (Clover, Follen, \& Hall, 1998).

The friends realized that a conceptual platform to engage higher education stakeholders in conversations about sustainability in a creative, fun, and resonating way (like a good conversation at a great party), was exactly what was needed. Thus the Goggles Project was born-predicated on the assertion that engaging people in discussions of sustainable development requires a different approach.

Sponsored by a generous grant from the Social Sciences and Humanities Research Council of Canada, the friends gathered a team of creative thinkers to develop the idea further. The team met and discussed many ideas to "interrupt" people's lives on campus and find creative ways to get them talking about sustainability. The use of street theatre was seen as an excellent way to reach those who might not necessarily be reached by traditional academic offerings such as a focus group or lecture on sustainability.

The choice of street theatre as a medium was informed by a growing body of literature that demonstrates the benefits of using the arts in engaging people in thinking about and action for a sustainable future. Cohen-Cruz (2001) demonstrates the efficacy of street theatre in the past to discuss major social issues, and argues that street theatre has the ability to help push new questions onto the political agenda. Packalen (2009) claims that the arts can inspire empathy, evoke emotion and spark dialogue. For Packalen, the arts can examine the world critically and provide insights to better understand the problems we face and to build sustainable solutions. Further, Nadarajah and Yamamoto (2007) discuss the power of theatre in terms of building a culture around sustainability. In addition, Österlind (2008), and Sullivan et al. (2008), demonstrate through case studies, the benefits of using interactive theatre as a method to bring about social change. In particular, Sullivan and Lloyd (2006) found that interactive theatre was particularly beneficial in addressing community environmental issues in contrast to using traditional approaches.

The vision of the Goggles Project Inaugural Tour was to inspire all university stakeholders to think about how universities can contribute to a sustainable future. The goals included:

- Explaining in plain language what sustainability means

- Conveying the urgency of sustainability in a way that does not depress people

- Creating dialogue amongst all stakeholders in the university about higher education and sustainability

- To reach out to individuals on campus who may have never thought of sustainability and/or ESD in the past.

Street theatre was purposefully chosen for this project in order to achieve these goals. By performing on high foot traffic areas on campus, it was anticipated that the troupe would be able to bring their message and provoke discussions with students, faculty, staff and administrators from all facets of the campus

\section{Goggles Project-The Inaugural Tour}

The first Goggles Project Tour took place over a three-week period at the beginning of the academic school year (September-October). A troupe of four professional actors and a handler/communication expert travelled from Halifax to Vancouver by train, visiting nineteen university campuses and performing at least 4 street theatre events a day to a total audience of over 1000 people. After receiving location advice from sustainability campus contacts across the country, the troupe performed on university greens, the steps of administrative buildings, in pe- 
destrian walkways, cafeterias, and residences halls (we even performed in a loading zone once and nearly got run over).

The troupe engaged the audience in a thought-provoking way, asking them to rethink their understandings of sustainability and suggest solutions for the campus that go beyond reduce, reuse and recycle. The 15 - 20 minute street show introduced the playful and funny troupe of eccentric thinkers from the fictional Rethink University, as they delivered a lecture for a first-year undergraduate class called Rethink 101 (Figure 1). The show included an interactive quiz with the audience, stories of how Re-Think University came to be, descriptions of new ways seeing higher education's role in sustainability (with the use of goggles that help us see more clearly), and a sustainability pledge and rap! The troupe engaged their audiences, asking them to consider how universities may have contributed to unsustainable behaviour in the past, examine new ways of thinking about higher education for the future, and develop new perspectives on the foundations and purpose of the university given our desire for a healthy, prosperous and sustainable plane.

The messages and facts that the Goggles troupe shared with their audiences were a reminder of the challenges humanity and the planet face. However, the goal was not to focus on grim predictions for the future or on difficulties that may lie ahead. Rather, it was to encourage university stakeholders to refocus. The show therefore focused on being entertaining as well as information. The use of homemade goggles was particularly effective for injecting humour into the show. Whenever in the performance the troupe had a moment of clarity about sustainability, they put on goggles (made from recycled water bottles) to symbolize a transformation in their thinking (Figure 2). Audience members were also encouraged to wear the goggles, and were given cards that promoted the project and gave instructions for people make their own goggles.

At the end of the show, audience members were encouraged to talk to the troupe and record videos to document their own goggles moments (instances where they realized that something related to sustainability on campus must change), and/or to offer their thoughts on what universities could and/or should be doing to become leaders in creating a sustainable future (Figure 3). The videos were uploaded on the gogglesproject.org website so that viewers could see what university stakeholders across the country think about the university and sustainability.

\section{Lessons Learned-The Hits and Misses!}

The Goggles Project, although informed by scholarly research and experience, was a grand experiment. While there were many things that we did right, there are also things that we would do differently next time. The following section reflects on some of the "hits" and "misses" of the Goggles Project Tour, and discusses possible avenues to follow for subsequent iterations of the project.

First, and foremost, our experiences add to the literature that discusses the efficacy of using theatre as a medium to engage people in thinking about important societal issues (Cohen-Cruz, 2001; Nadarajah \& Yamamoto, 2007; Österlind, 2008; Sullivan et al., 2006; Sullivan \& Lloyd, 2006). Not only did people stop to be part of the audience, many individuals stayed around after the performance to talk with the troupe about their ideas on sustainability and the university. Many of the audience members said how much they appreciated the opportunity to reflect

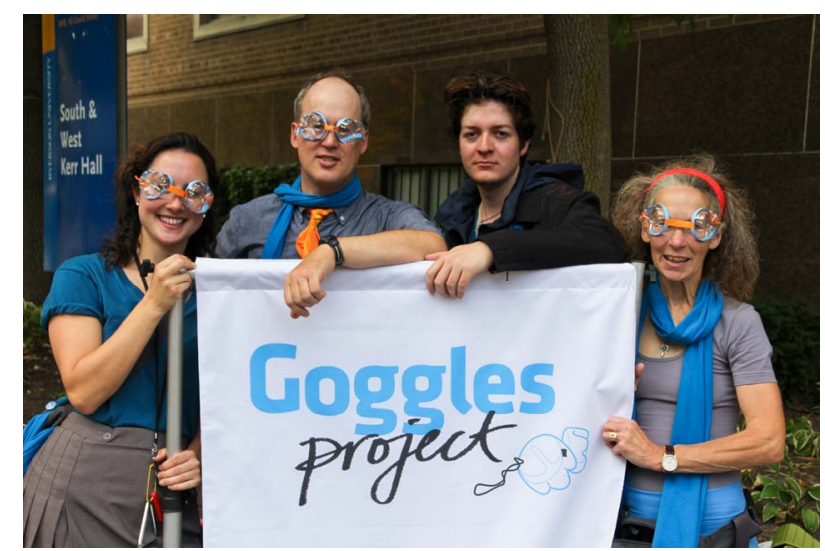

Figure 1.

The goggles project troupe.

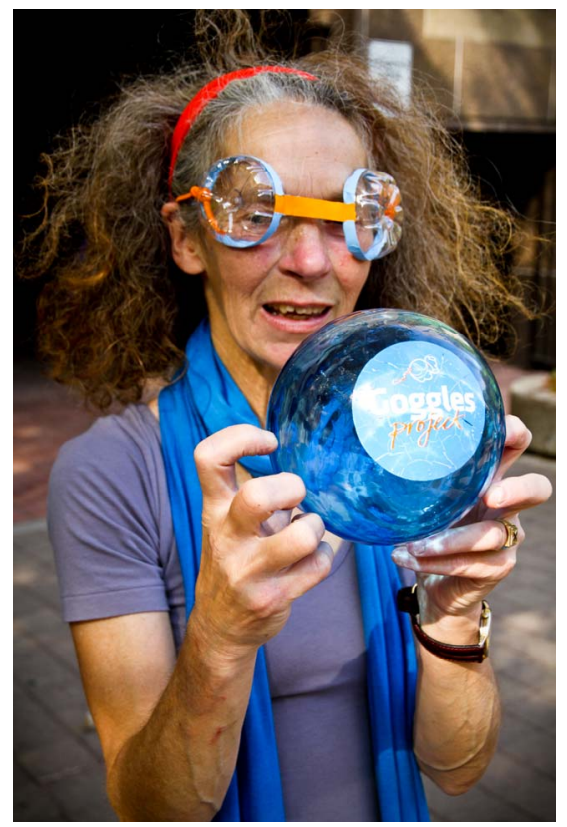

Figure 2.

The nutty professor has a "goggles" moment during Re-Think 101 lecture.

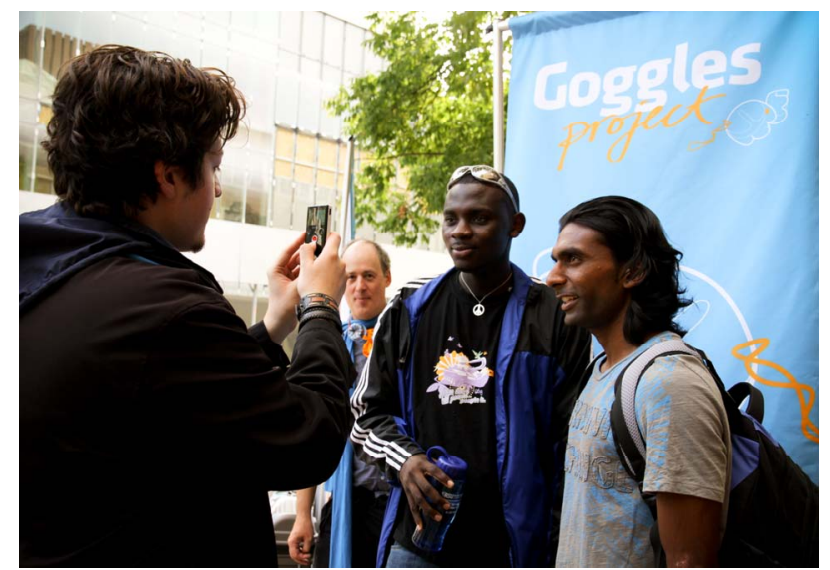

Figure 3.

Students at Ryerson University have their say on the goggles' website. 
on an issue that they were not often exposed to. As one student said:

"I am writing to say thank you for coming to our university and catching people as they bustled by. It is so easy for us to live in a bubble of oblivion-especially in a university setting. It seems almost contradictory, that in an institution teaching critical thinking, we become so absorbed in the day-to-day that we lose our perspective on the wider world. Thank you for making us question the way universities operate and for encouraging us to think about ways to change our institutions and the way we are educated.” (Rosalind Crump, Mount Allison University)

In addition, we learned that the delivery of heavy material (i.e. climate change, poverty, an war) can benefit from a light treatment in order to engage and not scare people away. The troupe found that being silly (i.e. physical comedy, rapping using humorous lyrics, etc.) during the show relaxed people and encouraged them into creative thinking.

We also found that the use of goggles made from recycled pop bottles throughout the performance and after the show was useful in engaging the audience. Not only were the goggles used as a metaphor for seeing differently, the physical presence of the goggles, and encouraging the audience to wear the goggles was brilliant way to put people at ease in order to generate innovative ideas. Anecdotally, the troupe found that when they asked an audience member to give their ideas on how the university could be more sustainable, their ideas were much more creative (i.e. have a herd of goats cut the lawns on campus) if they were asked to wear the goggles in responding, then if they did not (i.e. offer more courses related to the environment).

The same was true after the show when audience members were invited to give their own thoughts and ideas to be posted on the website. The troupe found that many of the audience members wanted to talk, and the website became full of innovative ideas and creative solutions that are currently not present in the literature (see www.googlesproject.org to view a selection of the videos from our first tour).

The team also admits to some "misses" along the way. First, we observed that people are afraid of being the first person to stop to watch a street performance. While we did our best to pre-advertise performances with sustainability groups on each university campus via social media (primarily via Twitter and Facebook), there were occasions where there was no pre-audience waiting for the show to happen and it was very difficult to get people to stop and watch even in heavily travelled areas. On the other hand, when we had a small crowd of people gathered before a show, people were more likely to stop and watch. Therefore, any future iteration of Goggles street theatre will attempt to maximize pre-audience size even if it means putting "ringers" in the audience.

Second, while the Goggles Project Tour was an attempt to reach stakeholders throughout the university, we found that the majority of our audiences were made up of students. While Students are an essential component of sustainability in higher education (Kagawa, 2007).), research shows that all stakeholders need to be involved in discussions and actions toward becoming models of sustainability (Filho, 2000; Keniry, 1995). Therefore future iterations of the Goggles Project will likely include guerrilla and disruptive theatre (i.e. the troupe breaking in on faculty meetings, administrative offices, etc.) to ensure that all stakeholders are reached.

\section{Conclusion}

Universities have the potential to become leaders in developing a sustainable future. The literature shows that becoming leaders in the sustainability movement requires both an awareness of sustainability amongst all stakeholders on campus, and openness to positive cultural change for sustainability in higher education.

The Goggles Project adds to the emerging body of literature that demonstrates the benefit of using creative acts in aiding in a cultural transformation within higher education toward sustainability. Further, the Goggles Project contributes to the sustainability in higher education literature by identifying conceptualizations of various campus stakeholders on the role that the university can play in creating a sustainable future.

It is our sincere hope that our manuscript offers guidance and inspiration to others wishing to engage in creative acts on campus in their own attempts to create positive cultural change for sustainability on their campus. Stay tuned for Goggles Project Take Two!

\section{Acknowledgements}

The Goggles Project was supported by a Research Dissemination grant from the Social Sciences and Humanities Research Council.

\section{REFERENCES}

Bachiorri, A., \& Puglisi, A. (2007). Promoting education for sustainability: A challenge for the university system. In W. Leal Filho, E. Manoloas, M. Sotirakou, \& G. Boutakis (Eds.), Higher education and the challenge of sustainability: Problems, promises and good practice (pp. 7-15). Orestiada: Environmental Education Center of Soufli.

Clover, D., Follen, S., \& Hall, B. (1998). The nature of transformation: environmental, adult and popular education. Toronto: Ontario Institute for Studies In Education.

Clugston, R. (1999). Introduction. In W. L. Filho (Ed.), Sustainability and university life. Frankfurt/M: Peter Lang.

Cohen-Cruz, J. (2001). Motion of the ocean: The shifting face of US theater for social change since the 1960s. Theatre, 31, 95-107. doi:10.1215/01610775-31-3-95

Cortese, A. D. (2003). The critical role of higher education in creating a sustainable future. Planning for Higher Education, 3, 15-22.

De la Harpe, B., \& Thomas, I. (2009). Curriculum change in universities: Conditions that facilitate education for sustainable development. Journal of Education for Sustainable Development, 3, 75-85. doi: $10.1177 / 097340820900300115$

Filho, W. L. (2000). Communicating sustainability: Some international considerations and challenges. In W. L. Filho (Ed.), Communicating sustainability (pp. 11-23). Frankfurt: Peter Lang.

Filho, W. L. (2005). Handbook of sustainability research. Frankfurt: Peter Lang.

Kagawa, F. (2007). Dissonance in students' perceptions of sustainable development and sustainability: Implications for curriculum change. International Journal of Sustainability in Higher Education, 8, 317338. doi:10.1108/14676370710817174

Keniry, J. (1995). Ecodemia. Washington DC: National Wildlife Federation.

Kezar, A. (2009). Change in higher education: Not enough, or too much? Change: The Magazine of Higher Learning.

http://www.tandfonline.com

Kezar, A. J., \& Eckel, P. D. (2002). The effect of institutional culture on change strategies in higher education: Universal principles or culturally responsive concepts. The Journal of Higher Education, 73, 435460. doi:10.1353/jhe.2002.0038 
Mcmillin, J., \& Dyball, R. (2009). Developing a whole-of-university approach to educating for sustainability. Journal of Education for Sustainable Development, 3, 55-64. doi:10.1177/097340820900300113

Nadarajah, M., \& Yamamoto, A. T. (2007). Urban crisis: Culture and sustainability of cities.

Oepen, M. (2000). Environmental communication for sustainable development. In M. Oepen, \& W. Hamacher (Eds.), Communicating the environment: Environmental communication for sustainable development (pp. 32-37). Frankfurt: Peter Lang.

Ornetzeder, M., \& Rohracher, H. (2005). Social learning, innovation and sustainable technology. In W. L. Filho (Ed.), Handbook of sustainability research (PP. 147-176), Frankfurt/M.: Peter Lang.

Orr, D. (1992). Ecological literacy: Education and transition to a postmodern world. Albany: State University of New York Press.

Österlind, E. (2008). Acting out of habits: Can theatre of the oppressed promote change? Boal's theatre methods in relation to Bourdieu's concept of habitus. Research in Drama Education: The Journal of Applied Theatre and Performance, 13, 71-82.

Packalen, S. (2009). Culture and sustainability. Sweden: Malardalen University.

Sullivan, et al. (2008). Theatre of the oppressed and environmental justice communities: A transformational therapy for the body politic. Journal of Health Psychology, 13, 166-179. doi:10.1177/1359105307086710

Sullivan, J., \& Lloyd, R. S. (2006). The forum theatre of Augusto Boal: A dramatic model for dialogue and community-based environmental science. Local Environment, 11, 627-646. doi:10.1080/13549830600853684

United Nations Education Science and Cultural Organization (UNE SCO) (2005). Draft international implementation scheme decade of sustainable environment. Paris: UNESCO. http://portal.unesco.org/education/en/ev.php-URL_ID=36025\&URL DO=DO_TOPIC\&URL_SECTION=201.html

United Nations (2002). United nations general assembly resolution $59 / 237$.

UNESCO, UNEP (1977) The Tbilisi declaration. Moscow: UNESCOUNEP press.

UNESCO (1997). Thessaloniki Declaration. Gland: UNESCO.

Wals, A. E. J., \& Jickling, B. (2002). Sustainability in higher education: From doublethink and newspeak to critical thinking and meaningful learning. International Journal of Sustainability in Higher Education, 3, 221-232. doi: $10.1108 / 14676370210434688$

World Commission on Environment and Development (WCED) (1987). Our common future. Oxford: Oxford University Press.

Wright, T. (2004). The evolution of sustainability declarations in higher education. In P. B. Corcoran, \& A. E. Wals (Eds.), Higher education and the challenge of sustainability (pp. 7-19), Dordrecht: Kluwer Academic Publishers. doi:10.1007/0-306-48515-X_2

Wright, T. (2010). University presidents' conceptualizations of sustainability in higher education. International Journal of Sustainability in Higher Education, 11, 61-73. doi:10.1108/14676371011010057 